\title{
SERUM LIPIDS IN INFECTIOUS HEPATITIS AND OBSTRUCTIVE JAUNDICE ${ }^{1}$
}

\author{
By MARGARET J. ALBRINK, ${ }^{2}$ EVELYN B. MAN, AND JOHN P. PETERS \\ (From the Department of Internal Medicine, Yale University School of Medicine, New Haven)
}

(Submitted for publication December 13, 1949; accepted, March 6, 1950)

\begin{abstract}
Although changes in the serum lipids in liver disease have long been recognized, many of the studies preceded the development of accurate methods and failed to include concomitant observations on the lipid constituents other than cholesterol. Infectious hepatitis and obstructive jaundice, because they provide a wide range of abnormal lipids, offer a particularly good opportunity to study the interrelations of the serum lipids. For this reason, in addition to their diagnostic value, it seemed desirable to report the studies made by this laboratory of the serum total and fractionated cholesterol, the phospholipids, the total fatty acids and the neutral fat in these conditions.

The present study is an extension of the study of the serum lipids in liver disease previously reported (1).
\end{abstract}

\section{METHODS AND CLINICAL MATERIAL}

Free and total cholesterol, lipid phosphorus and total fatty acids were determined on serum from patients who had fasted over night, and neutral fat was calculated from the above figures by methods previously described (2). The values for each are expressed in the terms in which they are measured: cholesterol as milligrams per cent, phospholipids as milligrams per cent of lipid phosphorus, fatty acids as milliequivalents per liter, and neutral fat as milliequivalents of fatty acids in the neutral fat. The subjects of the study were patients in the New Haven Hospital from 1945 to 1949.

\section{RESULTS}

Infectious hepatitis. There were 94 determinations of serum lipids from 41 patients: 12 with homologous serum jaundice, 20 with typical infectious hepatitis, and nine with atypical features or

\footnotetext{
1 This investigation was supported (in part) by a research grant from the Division of Research Grants and Fellowships of the National Institutes of Health, U. S. Public Health Service, and by a grant from the Fluid Research Fund, Yale University School of Medicine.

2 During tenure of a National Institutes of Health Postdoctorate Research Fellowship.
}

complicating factors. The pertinent data on these patients are listed in Table I. The day of illness was calculated from the date of appearance of symptoms. The serum lipids were in all cases determined after the onset of jaundice, and in a number of cases were determined serially throughout the remainder of the illness. Although the total cholesterol did not usually depart from the normal range of 125 to $265 \mathrm{mg}$. per cent (2), marked fluctuations were revealed by serial determinations in a few typical cases. When measured soon after the appearance of jaundice and while biliary obstruction was still relatively complete, the total cholesterol was usually in the lower half of the normal range. This was immediately followed by a prompt and rapid rise to a peak, as a rule to the middle or upper limits of the normal range. This rise was associated with beginning resolution of the hepatitis as evidenced by the reappearance of bile in the stools and urobilinogen in the urine, and by clinical improvement. There was subsequently a fall to the middle normal range about a week later, associated with the gradual fading of jaundice. In addition, the ratio of free to total cholesterol, normally between 0.24 and $0.32(2,3)$, was initially markedly elevated, falling steadily in subsequent determinations.

Eighteen patients were followed until their lipids had returned to normal. This occurred from 14 to 60 days after the onset of symptoms, with an average of 37 days, at which time the patients seldom had symptoms other than easy fatigability.

Values for cholesterol in patients who were not followed with frequent determinations appeared to be consistent with the course that has been described. Frequently the initial cholesterol was quite high, suggesting that the early low phase had been missed.

Atypical features about the cholesterol values in some of the patients require comment. There 
were eight patients in whom the total cholesterol fell below the normal lower limit of $125 \mathrm{mg}$. per cent. Of these, cases 36, 18 and 27, had low cholesterols early in the course of their illnesses, one (No. 36) as low as $54 \mathrm{mg}$. per cent. Although No. 18 suffered a relapse a month later, recovery was otherwise uncomplicated in these three cases.
On the other hand, the three fatalities in the series (Nos. 10, 11, and 41) all had low total cholesterols. Case 41 was further remarkable by having complete absence of esters in one determination. The remaining two cases (Nos. 34 and 37) had low cholesterols associated with unusually severe cases of hepatitis.

TABLE I

Serum lipids in hepatitis

\begin{tabular}{|c|c|c|c|c|c|c|c|c|c|c|c|c|c|c|c|}
\hline & \multirow{2}{*}{ No. } & \multirow{2}{*}{$\begin{array}{l}\text { Unit } \\
\text { no. }\end{array}$} & \multirow{2}{*}{ Age } & \multirow{2}{*}{ Sex } & \multirow{2}{*}{$\begin{array}{c}\text { Dura- } \\
\text { tion }\end{array}$} & \multicolumn{3}{|c|}{ Cholesterol } & \multirow{2}{*}{$\underset{\mathbf{P}}{\text { Lipid }}$} & \multirow{2}{*}{$\frac{\text { Lipid P* }}{\text { Free C }}$} & \multicolumn{2}{|c|}{ Fatty acid } & \multirow{2}{*}{$\begin{array}{c}\text { Bili- } \\
\text { rubin }\end{array}$} & \multirow{2}{*}{$\begin{array}{l}\text { Icterus } \\
\text { index }\end{array}$} & \multirow{2}{*}{ Remarks } \\
\hline & & & & & & Total & Free & $\%$ Free & & & Total & $\underset{\text { fat }}{\text { Neutral }}$ & & & \\
\hline 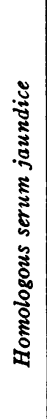 & $\begin{array}{l}1 \\
2 \\
3 \\
4\end{array}$ & $\begin{array}{l}\text { B72956 } \\
\text { A27118 } \\
\text { C6857 } \\
\text { A79633 } \\
\\
\text { C6694 } \\
7052 \\
54732 \\
\text { B83126 } \\
\text { C26499 } \\
\text { B99964 } \\
\text { JH } \\
\text { C10786 }\end{array}$ & $\begin{array}{l}57 \\
53 \\
71 \\
36\end{array}$ & $\begin{array}{l}\text { M } \\
\text { F } \\
\mathbf{M} \\
\text { F } \\
\text { F }\end{array}$ & $\begin{array}{r}\text { days } \\
15 \\
21 \\
9 \\
13 \\
22 \\
43 \\
36 \\
6 \\
15 \\
35 \\
28 \\
6 \\
15 \\
4 \\
31 \\
3\end{array}$ & $\begin{array}{l}m g . \% \\
183 \\
253 \\
134 \\
167 \\
177 \\
162 \\
208 \\
226 \\
150 \\
247 \\
135 \\
130 \\
269 \\
113\end{array}$ & \begin{tabular}{|r|}
$m g . \%$ \\
141 \\
167 \\
101 \\
126 \\
58 \\
51 \\
54 \\
211 \\
117 \\
135 \\
105 \\
96 \\
75 \\
84 \\
40 \\
108
\end{tabular} & $\begin{array}{l}77 \\
66 \\
75 \\
76 \\
33 \\
32 \\
26 \\
93 \\
78 \\
55 \\
78 \\
74 \\
28 \\
76 \\
72\end{array}$ & $\begin{array}{r}m g . \% \\
15.2 \\
19.3 \\
11.5 \\
16.6 \\
10.3 \\
9.5 \\
9.1 \\
20.4 \\
11.4 \\
16.0 \\
12.6\end{array}$ & $\begin{array}{r}0.083 \\
0.094 \\
0.078 \\
0.103 \\
0.115 \\
0.115 \\
0.102 \\
0.080 \\
0.067 \\
0.092 \\
0.085 \\
0.085 \\
\\
<0.000 \\
0.085\end{array}$ & $\begin{array}{c}\text { meq/L } \\
19.9 \\
27.1 \\
20.6 \\
29.0 \\
14.8 \\
12.4 \\
15.4 \\
19.8 \\
17.2 \\
18.9 \\
15.4 \\
18.2 \\
18.5 \\
15.5 \\
6.3 \\
19.3\end{array}$ & $\begin{array}{l}m e q / L \\
10.0 \\
13.9 \\
13.3 \\
18.3 \\
5.7 \\
4.0 \\
6.6 \\
7.6 \\
9.6 \\
6.7 \\
7.3 \\
7.7\end{array}$ & $\begin{array}{r}m g . \% \\
5.0 \\
7.3 \\
15.3 \\
24.6 \\
6.4 \\
1.7 \\
11.5 \\
26.0 \\
20.6 \\
5.8 \\
1.8 \\
21.0\end{array}$ & & $\begin{array}{l}\text { Halowax poisoning. Possible } \\
\text { homologous serum jaundice. } \\
\text { Much improved by 30th day. } \\
\text { Convalescent. } \\
\text { Diabetes and hypertension. } \\
\text { Gastric ulcer, malnourished. } \\
\text { Slow recovery. } \\
\text { Protracted course, malnourished. } \\
\text { Died on ninth day in hepatic } \\
\text { failure. } \\
\text { Died a few days later in hepatic } \\
\text { failure. }\end{array}$ \\
\hline 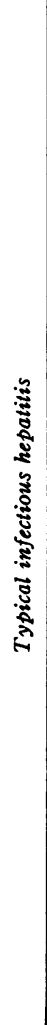 & $\begin{array}{l}24 \\
25 \\
26 \\
27\end{array}$ & $\begin{array}{l}\text { B78510 } \\
\text { B39643 } \\
\text { B76034 } \\
\text { C545 } \\
\\
\text { C15957 } \\
\text { C25403 } \\
\text { C21165 }\end{array}$ & $\begin{array}{l}22 \\
45 \\
65 \\
55\end{array}$ & $\begin{array}{l}\underset{\mathbf{F}}{\mathrm{M}} \\
\stackrel{\mathrm{F}}{\mathbf{M}}\end{array}$ & $\begin{array}{r}12 \\
26 \\
14 \\
19 \\
23 \\
26 \\
60 \\
5 \\
12 \\
20 \\
27 \\
13 \\
17 \\
7 \\
5 \\
23 \\
53 \\
120 \\
10 \\
14 \\
22 \\
29 \\
13 \\
14 \\
15 \\
15 \\
23 \\
40 \\
10 \\
13 \\
24 \\
7 \\
14 \\
40 \\
7 \\
8 \\
20 \\
25 \\
15 \\
19 \\
22 \\
26 \\
31 \\
37 \\
42 \\
45 \\
57 \\
85 \\
45\end{array}$ & $\begin{array}{l}179 \\
249 \\
159 \\
242 \\
230 \\
221 \\
242 \\
177 \\
279 \\
225 \\
252 \\
163 \\
230 \\
188 \\
92 \\
209 \\
151 \\
175 \\
146 \\
255 \\
249 \\
253 \\
226 \\
191 \\
193 \\
262 \\
195 \\
144 \\
207 \\
223 \\
216 \\
102 \\
143 \\
183 \\
159 \\
280 \\
182 \\
196 \\
148 \\
195 \\
200 \\
185 \\
179 \\
180 \\
157 \\
152 \\
205 \\
155 \\
285\end{array}$ & $\begin{array}{r}68 \\
75 \\
113 \\
144 \\
106 \\
75 \\
67 \\
146 \\
97 \\
63 \\
64 \\
124 \\
68 \\
162 \\
44 \\
83 \\
47 \\
45 \\
84 \\
125 \\
67 \\
66 \\
178 \\
91 \\
108 \\
144 \\
54 \\
43 \\
76 \\
165 \\
67 \\
50 \\
43 \\
49 \\
56 \\
145 \\
66 \\
63 \\
119 \\
156 \\
134 \\
83 \\
62 \\
52 \\
50 \\
43 \\
53 \\
45 \\
78\end{array}$ & $\begin{array}{l}38 \\
30 \\
71 \\
59 \\
46 \\
34 \\
27 \\
83 \\
35 \\
28 \\
25 \\
76 \\
30 \\
80 \\
48 \\
40 \\
31 \\
26 \\
60 \\
45 \\
27 \\
26 \\
79 \\
48 \\
56 \\
55 \\
28 \\
30 \\
37 \\
74 \\
31 \\
49 \\
30 \\
27 \\
35 \\
52 \\
36 \\
32 \\
30\end{array}$ & $\begin{array}{r}9.1 \\
11.3 \\
14.3 \\
10.0 \\
11.4 \\
20.9 \\
12.1 \\
11.7 \\
15.0 \\
7.8 \\
7.3 \\
10.4 \\
18.9 \\
9.3 \\
8.0 \\
7.8 \\
8.2 \\
8.9 \\
18.8 \\
9.6 \\
11.0 \\
15.6 \\
19.3 \\
17.6 \\
15.4 \\
12.5 \\
9.9 \\
10.3 \\
10.3 \\
10.0 \\
9.8 \\
11.7\end{array}$ & $\begin{array}{l}0.122 \\
0.092 \\
0.086 \\
0.095 \\
0.118 \\
0.097 \\
0.094 \\
0.075 \\
0.079 \\
0.078 \\
0.086 \\
0.090 \\
0.093 \\
0.085 \\
0.088 \\
0.098 \\
0.094 \\
0.095 \\
0.100 \\
0.091 \\
0.120 \\
0.100 \\
0.100 \\
0.104 \\
0.140 \\
0.144 \\
0.120 \\
0.134 \\
0.155 \\
0.120 \\
0.138 \\
0.074\end{array}$ & $\begin{array}{l}13.2 \\
13.9 \\
18.5 \\
21.1 \\
16.3 \\
14.7 \\
12.4 \\
20.6 \\
18.3 \\
14.6 \\
15.1 \\
25.5 \\
14.7 \\
24.6 \\
9.4 \\
16.7 \\
18.6 \\
12.3 \\
14.2 \\
16.8 \\
13.2 \\
14.4 \\
24.5 \\
18.9 \\
17.1 \\
17.5 \\
10.2 \\
13.7 \\
20.9 \\
15.5 \\
12.1 \\
10.4 \\
11.6 \\
13.5 \\
32.9 \\
14.3 \\
17.0 \\
24.0 \\
29.0 \\
25.4 \\
28.2 \\
28.7 \\
20.7 \\
23.3 \\
22.9 \\
19.6 \\
19.0 \\
17.0\end{array}$ & $\begin{array}{r}3.6 \\
5.4 \\
6.0 \\
2.7 \\
2.9 \\
9.7 \\
9.3 \\
8.1 \\
5.7 \\
2.0 \\
0.9 \\
3.6 \\
8.4 \\
6.2 \\
6.2 \\
3.3 \\
3.3 \\
5.6 \\
18.4 \\
5.7 \\
6.4 \\
14.4 \\
12.6 \\
13.5 \\
16.6 \\
18.4 \\
11.6 \\
14.5 \\
14.1 \\
9.9 \\
10.4 \\
4.8\end{array}$ & $\begin{array}{r}7.2 \\
17.6 \\
9.9 \\
11.7 \\
9.0 \\
4.4 \\
2.4 \\
2.2 \\
0.9 \\
4.2\end{array}$ & $\begin{array}{c}21.4 \\
5.4 \\
5.7 \\
\\
60 \\
40 \\
10\end{array}$ & Well by 23 rd day. \\
\hline
\end{tabular}


TABLE I-Continued

\begin{tabular}{|c|c|c|c|c|c|c|c|c|c|c|c|c|c|c|c|}
\hline & \multirow{2}{*}{ No. } & \multirow{2}{*}{$\begin{array}{l}\text { Unit } \\
\text { no. }\end{array}$} & \multirow{2}{*}{ Age } & \multirow{2}{*}{ Sex } & \multirow{2}{*}{$\begin{array}{c}\text { Dura- } \\
\text { tion }\end{array}$} & \multicolumn{3}{|c|}{ Cholesterol } & \multirow{2}{*}{$\underset{\mathbf{P}}{\text { Lipid }}$} & \multirow{2}{*}{$\frac{\text { Lipid P* }}{\text { Free C }}$} & \multicolumn{2}{|c|}{ Fatty acid } & \multirow{2}{*}{$\begin{array}{l}\text { Bili- } \\
\text { rubin }\end{array}$} & \multirow{2}{*}{$\begin{array}{l}\text { Icterus } \\
\text { index }\end{array}$} & \multirow{2}{*}{ Remarks } \\
\hline & & & & & & Total & Free & $\%$ Free & & & Total & $\begin{array}{c}\text { Neutral } \\
\text { fat }\end{array}$ & & & \\
\hline 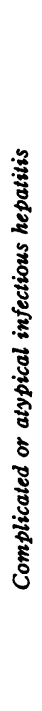 & $\begin{array}{l}36 \\
37 \\
38 \\
39\end{array}$ & $\begin{array}{l}\text { B56020 } \\
\text { C4579 } \\
\text { B73262 } \\
\text { B44434 }\end{array}$ & $\begin{array}{l}20 \\
56 \\
38 \\
63\end{array}$ & $\begin{array}{l}\mathbf{F} \\
\mathbf{F}\end{array}$ & $\begin{array}{r}\text { days } \\
18 \\
32 \\
28 \\
35 \\
56 \\
10 \\
17 \\
25 \\
47 \\
60 \\
75 \\
7 \\
21 \\
21 \\
35 \\
60 \\
8 \\
20 \\
27 \\
34 \\
41 \\
76 \\
14 \\
28 \\
50 \\
150 \\
154 \\
159 \\
164 \\
186\end{array}$ & $\begin{array}{c}m g . \% \\
180 \\
276 \\
93 \\
92 \\
134 \\
283 \\
442 \\
547 \\
957 \\
705 \\
622 \\
54 \\
76 \\
107 \\
236 \\
199 \\
\\
336 \\
400 \\
321 \\
284 \\
217 \\
142 \\
265 \\
238 \\
190 \\
209 \\
154 \\
123 \\
96\end{array}$ & $\begin{array}{r}m g . \% \\
151 \\
83 \\
58 \\
47 \\
45 \\
252 \\
416 \\
521 \\
839 \\
389 \\
180 \\
34 \\
66 \\
41 \\
70 \\
124 \\
268 \\
279 \\
132 \\
89 \\
68 \\
109 \\
74 \\
77 \\
190 \\
172 \\
116 \\
86 \\
47\end{array}$ & $\begin{array}{r}83 \\
30 \\
62 \\
51 \\
32 \\
89 \\
94 \\
95 \\
88 \\
55 \\
30 \\
63 \\
87 \\
38 \\
30 \\
62 \\
80 \\
69 \\
41 \\
31 \\
31 \\
77 \\
28 \\
32 \\
100 \\
82 \\
75 \\
70 \\
49\end{array}$ & $\begin{array}{r}m g . \% \\
12.2 \\
11.4 \\
5.4 \\
5.3 \\
6.2 \\
28.8 \\
42.5 \\
52.1 \\
84.8 \\
42.9 \\
5.7 \\
5.6 \\
9.9 \\
11.6 \\
12.5 \\
25.7 \\
25.6 \\
15.4 \\
11.7 \\
11.3 \\
9.6 \\
12.4 \\
13.0 \\
19.1 \\
9.8 \\
6.8 \\
4.7\end{array}$ & $\begin{array}{l}0.057 \\
0.094 \\
0.031 \\
0.036 \\
0.058 \\
0.106 \\
0.093 \\
0.093 \\
0.097 \\
0.218 \\
0.062 \\
0.030 \\
0.154 \\
0.114 \\
0.072 \\
0.083 \\
0.079 \\
0.089 \\
0.091 \\
0.114 \\
0.055 \\
0.119 \\
0.122 \\
0.082 \\
0.053 \\
0.037 \\
0.023\end{array}$ & $\begin{array}{c}\text { meg/L } \\
12.5 \\
17.5 \\
9.0 \\
7.2 \\
7.8 \\
27.4 \\
37.3 \\
47.1 \\
59.4 \\
47.4 \\
51.1 \\
7.6 \\
8.8 \\
15.1 \\
17.6 \\
17.7 \\
\\
29.9 \\
27.9 \\
21.9 \\
18.8 \\
14.9 \\
12.9 \\
15.8 \\
15.0 \\
15.8 \\
13.3 \\
11.8 \\
9.8 \\
9.2\end{array}$ & $\begin{array}{r}\text { meq } / L \\
4.6 \\
5.9 \\
5.0 \\
3.0 \\
2.0 \\
9.9 \\
11.9 \\
17.1 \\
7.0 \\
14.8 \\
3.8 \\
5.3 \\
7.7 \\
6.6 \\
8.5 \\
13.2 \\
9.9 \\
10.7 \\
7.1 \\
4.5 \\
8.8 \\
3.6 \\
3.3 \\
4.8 \\
5.1 \\
4.8 \\
5.2\end{array}$ & \begin{tabular}{r|}
17.0 \\
14.8 \\
8.2
\end{tabular} & $\begin{array}{r}100 \\
20 \\
100 \\
\\
25\end{array}$ & $\begin{array}{l}\text { Recurrent jaundice, ascites and } \\
\text { edema. } \\
\text { Much improved by 32nd day. } \\
\text { Severe course, possible subacute } \\
\text { atrophy of liver with eventual } \\
\text { recovery. } \\
\text { Protracted course complicated by } \\
\text { unstable diabetes. } \\
\text { Well by 80th day. } \\
\text { Early experimentally induced in- } \\
\text { fectious hepatitis. } \\
\text { Atypical infectious hepatitis in a } \\
\text { chronic alcoholic. } \\
\text { Adrenal insufficiency and he- } \\
\text { patitis. } \\
\text { Probable infectious hepatitis with } \\
\text { edema and ascites in a chronic } \\
\text { alcoholic. } \\
\text { Relapse of infectious hepatitis. } \\
\text { Severely ill. Ascites. Chronic } \\
\text { course terminated by death two } \\
\text { months after final studies. }\end{array}$ \\
\hline
\end{tabular}

${ }^{*}$ Lipid phosphorus (mg. per cent) -3.7

Free cholesterol (mg. per cent)

The question must be raised whether it may not be common for lipids to be low just as jaundice is appearing. The rapid rise from the rather low levels first found in those patients in whom early studies were made suggests that they were not usually determined at their lowest level but were already increasing. In experimentally induced hepatitis in human volunteers, Neefe (4) found a sharp drop in the cholesterol at the time that serum bilirubin began to rise, suggesting that a single low value early in the course of hepatitis may not necessarily imply a poor prognosis. However, a low total cholesterol is often an ominous prognostic sign. The low lipids in the terminal stages of toxic hepatitis (1) confirm this.

In only two of the 41 patients (Table I, Nos. 35 and 39) was the total cholesterol above $300 \mathrm{mg}$. per cent at any stage. It may be noteworthy that both these patients had diabetes. Without going into the problem of the lipids in diabetes it may be mentioned that a cholesterol above $300 \mathrm{mg}$. per cent occasionally is found in diabetics even in the absence of acidosis (5).

No cases fitting the description of cholangiolytic hepatitis, characterized by high serum cholesterol, described by Watson (6), were encountered.

Neutral fat is normally between 0 and 6 milliequivalents per liter, with an average of 3.1 . Within these limits, which represent twice the standard deviation above and below the mean, 95 per cent of the normal population should be expected to fall. However, sporadic values as high as 17 milliequivalents per liter occur in apparently normal persons (2). The neutral fat in the hepatitis cases was most variable, being frequently normal or only slightly elevated. There was a general tendency for the neutral fat to be elevated when the lipid phosphorus and cholesterol were high, but the rises in the latter were usually more pronounced than the rise in the neutral fat.

The lipid phosphorus is normally between 6.4 and $12 \mathrm{mg}$. per cent, with an average of 9.2 (2). The values found in the hepatitis cases ranged from 3.2 to $20.9 \mathrm{mg}$. per cent, excluding the two diabetics who had total cholesterols of over 300 mg. per cent, in whom the lipid phosphorus was somewhat higher. The lipid phosphorus paralleled the course of the total and free cholesterol. 
The relationship between the lipid phosphorus and the cholesterol fractions is given further consideration below.

Obstructive jaundice. There were 38 determinations on 24 patients with obstructive jaundice. These patients are listed in Table II with pertinent data. The jaundice was of variable duration and the obstruction varied from slight to complete. The cases are divided according to the completeness of the obstruction which, in the absence of quantitative measurements of stool bile pigments, was estimated roughly by the color of the stools, those patients with clay colored stools being classified as complete obstruction, and those with brown stools as incomplete. The 17 cases with complete obstruction had been jaundiced for from two weeks to one year. The etiology was usually neoplastic.

The cholesterol values of patients with complete obstruction have been listed in order of the duration of obstruction. In spite of the variability, certain trends are evident. The total cholesterol, which was usually in the upper range of normal when jaundice had been present for less than a month, became markedly elevated as jaundice persisted, in one case to as high as $588 \mathrm{mg}$. per cent. As a rule the ratio of free to total cholesterol rose as obstruction persisted. Two patients, who had

TABLE II

Serum lipids in obstructive jaundice

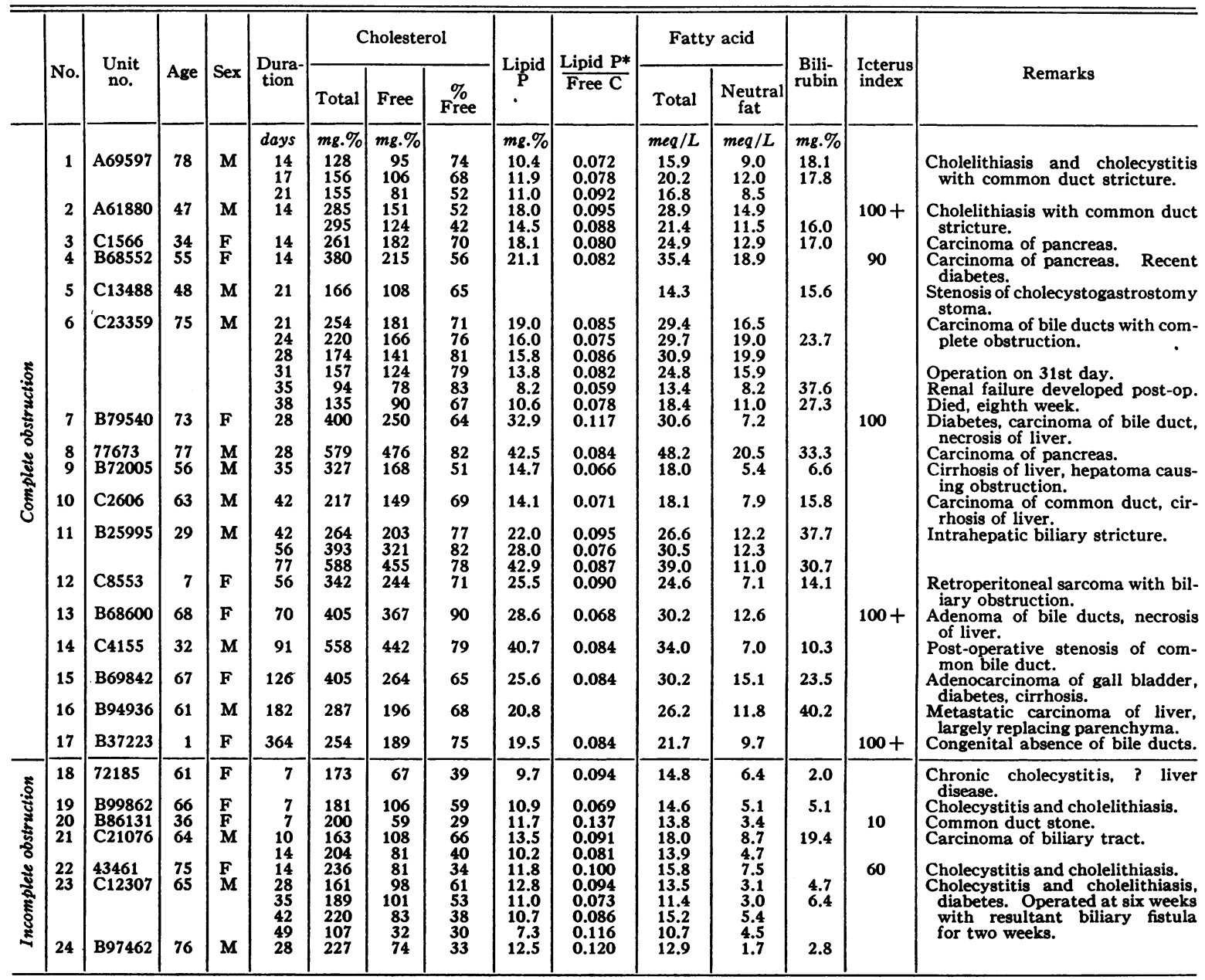

${ }^{*}$ Lipid phosphorus (mg. per cent) -3.7

Free cholesterol (mg. per cent) 
been jaundiced for six months and one year, had normal total cholesterols, although the ratio of free to total was still elevated.

In the patients with incomplete obstruction the changes were similar to, but less marked, than those found in early complete obstruction. Determinations on Nos. 6 and 23 (Table II) were made after the operative relief of obstruction, but at a time when most of the bile was escaping through biliary fistulae. The total cholesterol in each case was low, representing a marked drop from the preoperative determination. The per cent of free cholesterol was still elevated in No. 6 .

The neutral fat was almost invariably elevated in obstructive jaundice, though it rose in general less than the other lipid components. The phospholipids shared the rise in the other lipids. Values as high as $43 \mathrm{mg}$. per cent occurred, the highest values being found after three or four months of obstruction. The tendency of the lipid phosphorus to follow the free cholesterol is discussed below.

\section{DISCUSSION}

The foregoing data indicate that both hepatitis and mechanical biliary obstruction operate to raise the ratio of free to total cholesterol, that parenchymal damage tends to lower the total lipids while biliary obstruction tends to raise them to an extent roughly dependent on the completeness and duration of the obstruction. Although with less reliable methods it has been claimed that the cholesterol ratio is not as disturbed in obstructive jaundice as in infectious hepatitis (7), this was not true in this series. There was some overlap between the lipid values in infectious hepatitis and those in early or incomplete mechanical biliary obstruction.

The elevation of the ratio of free to total cholesterol was the first abnormality in the lipids to occur, and the last to return to normal. An exceptional case was No. 35 (Table I), the diabetic whose cholesterol ratio returned to normal while her total cholesterol was still over $600 \mathrm{mg}$. per cent. When an elevation of the lipids occurred in addition to the elevated cholesterol ratio, it involved first the free cholesterol, to a slightly less extent the lipid phosphorus, and least the neutral fat, the latter being quite variable. The consistently high values of the cholesterol ratio in the presence of jaundice suggest that it is related to the failure to excrete bile, whether this is due to parenchymal damage or mechanical obstruction.

In support of this theory is the fact that the ratio of free to total cholesterol is rarely as abnormal in cirrhosis with little or no icterus as it is in obstructive jaundice, although the liver damage may be far greater. Moreover, in the present series there was a rough relationship between the ratio of free to total cholesterol and two liver function tests which give some indication of the degree of obstruction, the serum bilirubin and the alkaline phosphatase. High serum bilirubin and alkaline phosphatase which were determined in a large number of the cases were always associated with a high cholesterol ratio. However, both low and high ratios occurred when the bilirubin and alkaline phosphatase were only slightly elevated.

The inadequacy of criteria for separating the effects of biliary obstruction from those of hepatocellular damage adds to the difficulty of defining the effects of each on the cholesterol ratio. The most abnormal ratios occurred in acute hepatitis when both the obstruction and the liver damage were the most severe. It is unlikely that mechanical obstruction ever exists without some degree of liver damage, although in most of the cases of common duct obstruction a high cholesterol ratio was associated with a normal or only slightly abnormal cephalin flocculation, thymol turbidity and prothrombin time. It is probably safe to conclude that hepatocellular damage and mechanical biliary obstruction, possibly through the same mechanism, both increase the ratio of free to total cholesterol, but that the former tends to lower and the latter to raise the total cholesterol.

The relationship between cholesterol and lipid phosphorus has been somewhat clarified by the present study. In a previous communication it was established that lipid phosphorus bore a rather close linear relationship to the total cholesterol in a large group of persons whose total cholesterols covered a wide range, but whose cholesterol ratios were normal (1). This relationship was altered in liver disease, particularly in infectious hepatitis and obstructive jaundice, by reason of a disproportionately great rise in the lipid phosphorus. Since this rise in the ratio of lipid phosphorus to total cholesterol seemed to be associated to a certain extent with the rise in the ratio of free to total cholesterol, it was decided to establish whether this 
might not indicate a closer relationship between the lipid phosphorus and the free cholesterol. In order to clarify this point, the relationship between lipid phosphorus and total cholesterol was compared with that between lipid phosphorus and free cholesterol in three groups of individuals. The first group, taken from our files and referred to as "normal," included normal subjects and patients with psychiatric disorders, nephrosis, and thyroid disease, providing a wide range of cholesterol values with normal cholesterol ratios. The total cholesterol values in the group ranged from 61 to $837 \mathrm{mg}$. per $100 \mathrm{cc}$. The second and third groups were composed of the patients with infectious hepatitis and obstructive jaundice respectively. Figure 1 shows the best straight lines representing the relationship of lipid phosphorus in these three groups to total and free cholesterol respectively. The lines have not been extended to the limits of observed figures in order to conserve space, but the directions are indicated in the figure. The factors for the slope and intercept of each line were derived by the method of least squares. In view of the constancy of the ratio of free to total cholesterol in normal serum, it is not surprising to find that in the normal group the lipid phosphorus bears a relationship to the free cholesterol. But where the infectious
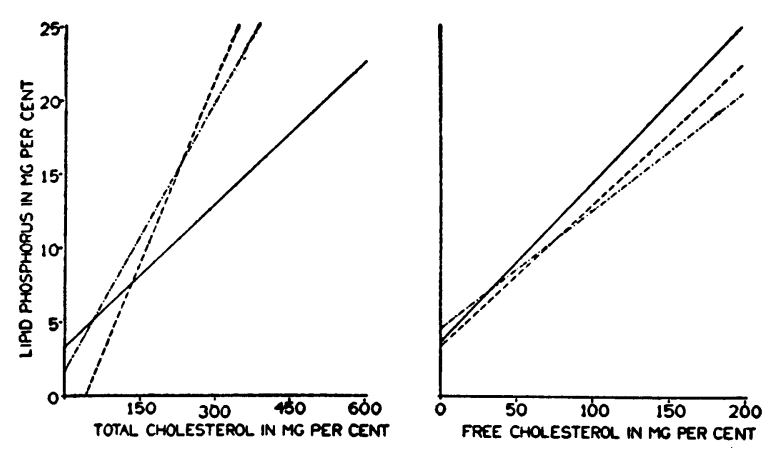

Fig. 1. The Relation of Lipid Phosphorus to Total and to Free Cholesterol

Solid lines represent normal subjects, broken lines patients with hepatitis, dot-dash lines patients with obstructive jaundice. The regression equations defining these lines are:
Normals
$\mathrm{LP}=0.0320 \mathrm{TC}+3.3, \quad \mathrm{LP}=0.1060 \mathrm{FC}+3.7$
Hepatitis
$\mathrm{LP}=0.8230 \mathrm{TC}-3.6, \quad \mathrm{LP}=0.0948 \mathrm{FC}+3.4$
Obstructive
$\mathrm{LP}=0.0600 \mathrm{TC}+1.7, \quad \mathrm{LP}=0.0816 \mathrm{FC}+4.1$. jaundice

hepatitis and obstructive jaundice groups are included the striking fact emerges that the relationship of lipid phosphorus to free cholesterol remains remarkably constant in all three groups, even in the presence of highly abnormal cholesterol ratios, while that to total cholesterol changes considerably. Thus the factor for the slope of the line which defines the regression of lipid phosphorus on total cholesterol was 0.032 for the normal group, 0.082 for the infectious hepatitis, and 0.060 for obstructive jaundice. In contrast to this, the slope of the regression of lipid phosphorus on the free cholesterol changed considerably less, the factors for the three groups being 0.106, 0.095 and 0.082 respectively. These factors indicate a close dependence of the lipid phosphorus on free cholesterol and suggest that its relationship with the total, which was previously described and has been recently confirmed by Ahrens and Kunkel (8), is a consequence of its dependence on the free. Moreover, for each group the lipid phosphorus bore a closer relation to the free than to the total cholesterol. Some notion of the closeness of the former relationship can be obtained from the standard deviation of the total population of lipid phosphorus from the regression line in relation to free cholesterol, which was $1.6 \mathrm{mg}$. per cent in the normal group, 2.1 in the obstructive jaundice group. It was somewhat greater, 3.1, in the infectious hepatitis group.

The explanation for the discrepancy between the factors, 0.095 and 0.082 , in infectious hepatitis and obstructive jaundice respectively is probably the inclusion in the former group of a rather large number of analyses made during the convalescent period when the lipids were relatively normal, while the obstructive jaundice group was studied chiefly when the lipids were highly abnormal. The factor of 0.082 is probably a fairer indication of this ratio in the active stages of hepatitis than the factor of 0.095 . Although the change in the slope from 0.106 to 0.082 appears to be relatively minor, the difference in the slopes is statistically significant. The reduction in the ratio of lipid phosphorus to free cholesterol in the jaundiced patients bore no obvious relation to the increase in the ratio of free to total cholesterol, though in individual cases the two ratios improved together.

A factor indicating the relationship between lipid phosphorus and free cholesterol for each 
individual case has been calculated from the following ratio (Tables I and II) :

\section{Lipid Phosphorus - 3.7 . Free Cholesterol}

If the relationship were perfect the ratio in each case would be identical with the factor for the slope of the lines; that is, 0.106 for the normals, 0.095 for the hepatitis cases and 0.082 for obstructive jaundice. The factor 3.7 is necessary because the line does not pass through the origin but rather through the lipid phosphorus axis at $3.7 \mathrm{mg}$. per cent in the normal group. While this intercept changes slightly in hepatitis and obstructive jaundice, it is constant enough to justify its use in the above ratio for evaluation of data, but has little actual significance since it is never actually reached. Moreover, free cholesterol appears to decrease less rapidly than lipid phosphorus as its extinction point is reached, causing the lipid phosphorus to be low in relation to the free cholesterol, particularly for lipid phosphorus values below 7.5. Most of the exceptionally low ratios of lipid phosphorus to free cholesterol in Tables I and II were associated with low lipids.

In one patient (Table 1, No. 35), the lipid phosphorus was elevated considerably out of proportion to the free cholesterol in several determinations. This patient had, in addition to protracted hepatitis, diabetes which was difficult to control, and may have had ketosis when these studies were made. In the hyperlipemia accompanying diabetic acidosis the lipid phosphorus may be elevated to a relatively greater extent than the cholesterol (9).

There are certain indications that it is the lecithin component of serum which is actually correlated with the free cholesterol. The choline-containing phospholipids constitute most of the serum phospholipids in man (10-12) and the proportion of choline-containing phospholipids remains constant in disease as well as in health (13). Since the sphingomyelin component of the choline phospholipids changes only negligibly in disease (14), the changes in lipid phosphorus must be due largely to changes in lecithin.

The significance of the constancy of this ratio is not clear. It may reflect a basic process in the liver, whereby fatty acids are apportioned to phospholipids and cholesterol. The antagonism between cholesterol and lecithin in some isolated situations, particularly in regard to cellular permeability, as reviewed by Foldes and Murphy (15), does not seem to be applicable to the situation in human serum.

Although the constancy of the ratio of lipid phosphorus to free cholesterol is more impressive than its departures from normal, the slight reduction in the ratio in infectious hepatitis and obstructive jaundice might indicate a decreased production of phospholipids by the liver. Zilversmit, Entenman, and Chaikoff (16) have shown that there is a marked decrease in the rate of incorporation of inorganic radioactive phosphorus into the plasma phospholipids when the liver is excluded from the circulation. If the ratio of incorporation of inorganic phosphorus is at all related to the rate of formation of new phospholipids, then a decreased rate of formation of phospholipids would be expected in liver disease.

The neutral fat fraction must be interpreted with caution since it must be calculated by difference from the values of the other lipid components and is therefore subject to a summation of all the technical errors (2). Moreover, the calculation involves the assumption that the relative proportions of phospholipids containing one and two fatty acids remains unchanged in disease. The constancy of the proportion of choline to serum phospholipid fractions in liver disease (13) suggests that this assumption may be correct. At present it can be said only that the neutral fat varied with the other lipid fractions in a general way.

\section{SUMMARY}

1. The serum lipids in 41 patients with hepatitis and 24 patients with obstructive jaundice are presented. The chronological pattern followed by the lipids in hepatitis is described.

2. The ratio of free to total cholesterol rose markedly in both conditions, being highest early in the icteric phase of infectious hepatitis, and in mechanical obstruction which was complete and had existed for some months.

3. The total cholesterol was lowest where the element of parenchymal damage was greatest, that is, in early or severe infectious hepatitis, and highest when the element of obstruction was greatest, in prolonged biliary obstruction. There was con- 
siderable overlap between the values in infectious hepatitis and those in partial or early obstruction of the common bile duct.

4. The phospholipids bore a close relationship to the free cholesterol even when the ratio of free to total cholesterol was markedly distorted. This relationship is discussed in some detail.

\section{BIBLIOGRAPHY}

1. Man, E. B., Kartin, B. L., Durlacher, S. H., and Peters, J. P., The lipids of serum and liver in patients with hepatic diseases. J. Clin. Invest., 1945, 24, 623.

2. Peters, J. P., and Man, E. B., The interrelations of serum lipids in normal persons. J. Clin. Invest., 1943, $22,707$.

3. Sperry, W. M., The relationship between total and free cholesterol in human blood serum. J. Biol. Chem., 1936, 114, 125.

4. Neefe, J. R., Stokes, J. Jr., Reinhold, J. G., and Lukens, F. D. W. Hepatitis due to the injection of homologous blood products in human volunteers. J. Clin. Invest., 1944, 23, 836.

5. Man, E. B., and Peters, J. P., Serum lipoids in diabetes. J. Clin. Invest., 1935, 14, 579.

6. Watson, C. J., and Hoffbauer, F. W., Liver function in hepatitis. Ann. Int. Med., 1947, 26, 813.

7. Epstein, E. Z., and Greenspan, E. B., Clinical significance of the cholesterol partition of the blood plasma in hepatic and in biliary diseases. Arch. Int. Med., 1936, 58, 860.

8. Ahrens, E. H., Jr., and Kunkel, H. G., The relationship between serum lipids and skin xanthomata in eighteen patients with primary biliary cirrhosis. $\mathrm{J}$. Clin. Invest., 1949, 28, 1565.

9. Man, E. B., and Peters, J. P., Lipoids of serum in diabetic acidosis. J. Clin. Invest., 1934, 13, 237.

10. Taurog, A., Entenman, C., and Chaikoff, I. L., The choline-containing and non-choline-containing phospholipids of plasma. J. Biol. Chem., 1944, 156, 385.

11. Hack, M. H., Estimation of the phospholipides in human blood. J. Biol. Chem., 1947, 169, 137.

12. Sinclair, R. G., The lecithin, cephalin, and sphingomyelin content of serum. I. As indicated by the choline-phosphorus and nitrogen-phosphorus ratios. J. Biol. Chem., 1948, 174, 343.

13. Albrink, M. J., The choline-containing phospholipids of serum. J. Clin. Invest., 1950, 29, 46.

14. Thannhauser, S. J., Serum lipids and their value in diagnosis. New Eng. J. Med., 1947, 237, 515.

15. Foldes, F. F., and Murphy, A. J., Distribution of cholesterol, cholesterol esters, and phospholipid phosphorus in normal blood. Proc. Soc. Exper. Biol. \& Med., 1946, 62, 215.

16. Zilversmit, D. B., Entenman, C., and Chaikoff, I. L., The measurement of the turnover of the various phospholipides in liver and plasma of the dog and its application to the mechanism of action of choline. J. Biol. Chem., 1948, 176, 193. 